\title{
0 mal-estar da experiência no século XXI: desafios para uma nova pedagogia universitária
}

\section{The evil being of experience in the 21st century: challenges for a new university pedagogy}

\author{
Adriano José Hertzog Vieira* \\ Márcio Tascheto da Silva* \\ Bernadete Maria Dalmolin ${ }^{* *}$
}

\begin{abstract}
Se não é possível defender uma prática educativa que se contente em girar em torno do "senso comum", também não é possível aceitar a prática educativa que, zerando o "saber de experiência feito", parta do conhecimento sistemático do(a) educador(a) (FREIRE, 2008, p. 58-59).
\end{abstract}

\section{Resumo}

Com o objetivo de potencializar a extensão como mobilizadora da aprendizagem na educação superior, no presente artigo tematizam-se o Manifesto de Córdoba e sua crítica ao modelo instrucionista, no qual a docência detém a soberania do ensino. Em vista disso, argumenta-se, com base em Walter Benjamin (1994), acerca da abstenção da experiência na sociedade capitalista dos séculos XX e XXI e suas repercussões nefastas para o processo de assujeitamento. Em Jean Piaget (2008), busca-se referenciar a experiência como elemento fundamental para que o processo de aprendizagem se realize, tornando-se constituidor das subjetividades. Por fim, busca-se identificar na extensão universitária seu potencial significante para a construção de uma nova pedagogia universitária na qual a experiência é o elemento mobilizador dos processos de conhecer/saber.

Palavras-chave: Aprendizagem. Experiência. Extensão. Pedagogia. Universidade.

\section{Abstract}

With the aim of enhancing extension as a mobilizer of learning in higher education, this article thematizes the Cordoba Manifest and its critique of the instructional model, in which teaching holds the sovereignty of teaching. In view of this, it is argued, based on Walter Benjamin (1994), about the abstention of experience in capitalist society of the twentieth and twenty-first and its disastrous consequences for the resignation process.

\author{
Recebido em 18/01/2018 - Aprovado em 13/05/2018 \\ http://dx.doi.org/10.5335/rep.v25i3.8565
}

Bacharel e licenciado em Filosofia (Unilasalle), mestre em Educação (Unisinos) e doutor em Educação (UCB). Assessor da Vice-Reitoria de Extensão e Assuntos Comunitários (gestão 2014-2018) da Universidade de Passo Fundo. E-mail: adrianojhvieira@gmail.com

** Licenciado em História, mestre e doutor em Educação. Docente no curso de Pedagogia da Universidade de Passo Fundo. Coordenador da Divisão de Extensão (gestão 2012-2018) na mesma instituição. E-mail: tascheto@upf.br

*** Graduada em Enfermagem e Obstetrícia (UFPel), residência em Saúde Mental Coletiva, especialização em Administração Estratégica em Saúde Mental Coletiva, mestra e doutora em Saúde Pública (USP). Docente e pesquisadora da Universidade de Passo Fundo. Vice-Reitora de Extensão e Assuntos Comunitários (gestão 2012-2018) na mesma instituição. E-mail: bernadalmolin@uol.com.br 
Jean Piaget (2008) seeks to refer to experience as a fundamental element for the learning process to take place, becoming a constituent of subjectivities. Finally, it is sought to identify in university extension its significant potential for the construction of a new university pedagogy in which experience is the mobilizing element of the processes of knowing/knowing.

Keywords: Experience. Extension. Learning. Pedagogy. University.

\section{Introdução}

Celebrar um aniversário é mais do que organizar uma festa. Trata-se de uma oportunidade profunda para reflexão, retomadas e decisões de rumos da vida. Em 2018, comemoramos os 100 anos do Manifesto de Córdoba. Longe de ser apenas um documento, o manifesto é um marco da reestruturação das universidades de toda a América Latina. No miolo das reinvindicações dos estudantes de Córdoba, situa-se a problemática do modelo de educação que sustenta a pedagogia universitária. No primeiro centenário do manifesto, quer-se comemorar os avanços da educação superior, mas também, e sobretudo, apontar desafios que possam qualificar cada vez mais a formação dos jovens latino-americanos e promover a construção de um conhecimento vivo, capaz de atender as reais necessidades da sociedade do nosso tempo.

No texto que segue, buscou-se, primeiramente, contextualizar o Manifesto de Córdoba, sublinhando seu importante papel para a reestruturação das universidades. Tal documento, como produto da reflexão e da ação de estudantes, traduz o desejo dos jovens universitários de reconhecer-se como sujeitos do conhecimento. Em suas manifestações, os estudantes denunciam o assujeitamento inerente ao modelo educativo instrucionista, baseado na informação como repasse de conteúdo e na supremacia do docente. Reivindicam, por sua vez, uma proposta educativa mais vivencial, baseada na experiência e na cultura como produto dos saberes resultantes de todas as ações humanas, tanto de dentro da universidade como de fora dela.

A abstenção da experiência no mundo moderno é o tema tratado no segundo ponto do artigo. Com base no pensamento do filósofo alemão Walter Benjamin (1994), buscou-se argumentar acerca do prejuízo causado pela ausência da experiência na cultura atual, e, em diálogo com alguns comentaristas do filósofo, pontuaram-se as características do sujeito dos últimos dois séculos, encarcerado na ilusão da opinião, do trabalho, da falta de tempo e do excesso de informação. De modo geral, todas essas características fazem-se presentes nos modelos de organização do ensino nas instituições de educação.

No terceiro ponto, explora-se a categoria de experiência proposta pelo epistemólogo suíço Jean Piaget (2008). Apesar de crítico do empirismo, Piaget argumenta em torno da necessidade da experiência para a constituição do sujeito enquanto ser 
de conhecimento. Busca-se, com os elementos propostos pelo próprio autor, justificar a prerrogativa da experiência como eixo mobilizador de toda a aprendizagem, sobretudo na educação superior.

Finalmente, identifica-se a extensão como potência para a reestruturação da pedagogia universitária, focada na experiência. Na atualidade, tem sido cada vez mais recorrente a indicação das chamadas metodologias inovadoras como forma de significar o ensino. A extensão, por sua característica de relação com a realidade e seu escopo experiencial, constitui-se meio privilegiado para a pretendida significação da aprendizagem.

Espera-se, com o trabalho desenvolvido neste estudo, contribuir para a qualificação da educação superior, tendo os sujeitos do processo cognitivo - educadores e educandos - como autores de uma trajetória autônoma e promotora da integralidade do ser humano, em vista de uma sociedade da dignidade, da justiça, da equidade e de uma vida com mais qualidade, em todos os sentidos. Parece ter sido este o grande intento dos jovens de Córdoba, comemorado no ano de 2018.

\section{0 que manifestou o manifesto?}

No período que sucedeu a primeira grande guerra, vivia-se em todo o mundo uma atmosfera de perplexidade pela destruição bélica, alavancada pela máquina industrial recém estabelecida, o desejo de reconstrução e uma ressentida pauperização dos países subdesenvolvidos. O desejo de mudanças sociais ensopou a massa juvenil universitária e produziu movimentos estudantis em todo o mundo.

$\mathrm{Na}$ Argentina, a atmosfera de renovação inspirada pelo desejo de saber dos jovens universitários, mobilizados pela busca do lugar de sujeitos da aprendizagem, espalhava-se por todos os recantos, exceto em Córdoba. As classes dominantes da província reprimiam as manifestações estudantis, e a universidade era um refúgio do conservadorismo decadente. As lideranças estudantis de Córdoba, conhecedoras do movimento de renovação em todo o mundo e, particularmente, na América Latina, promoveram uma grande manifestação, com ocupações de prédios da Universidade de Córdoba e reinvindicações contundentes em relação a um novo jeito de conceber a educação universitária. No documento escrito pelos estudantes, conhecido como Manifesto de Córdoba, podemos ler:

Nosso regime universitário - mesmo o mais recente - é anacrônico. Está fundado sobre uma espécie de direito divino; o direito divino do professorado universitário. Cria-se a si mesmo. Nele nasce e nele morre, mantendo um distanciamento olímpico. [...] A autoridade, em um lar de estudantes, não se exercita mandando, mas sugerindo e amando: ensinando (1918, não paginado). 
As reivindicações dos estudantes de 1918 focavam um sistema universitário anacrônico, pautado no autoritarismo docente. A grande questão de fundo era as noções de ciência e de educação predominantes, fundadas na racionalidade instrumental, eurocêntrica e monometódica. Tratava-se de problematizar um modo de ensinar na universidade, portanto, de repensar a pedagogia universitária.

A soberania do discurso ensinante, unilateralizado pela figura do professor, com predomínio da doutrinação em detrimento da experimentação, era a característica da docência denunciada pelos estudantes. A experiência aceita como fonte do conhecimento válido à universidade era aquela produzida pela razão monometódica cartesiana. Ao reivindicar um outro modo de fazer a educação universitária, os estudantes pediam um espaço para o saber vivido, produzido pela própria dinâmica biográfica dos sujeitos e da comunidade. É nesse contexto que a extensão universitária ganha o estatuto de abertura à comunidade.

Ao longo de quase cem anos e após muitos focos de ensaios da transformação pretendida, a universidade avançou menos do que se esperava em seu modo de ensinar. Na estrutura dissociativa da instituição universitária, a experiência produzida pela cultura das comunidades segue marginal, invalidada pelo paradigma da razão instrumentalizada e impedida pela predominância do ensino instrucionista, sustentado pela discursividade conteudista. É o reposicionamento do sujeito no universo da experiência o grande desafio da pedagogia universitária na contemporaneidade.

\section{A experiência deletada: contribuições de Walter Benjamin}

No célebre ensaio de 1933 "Experiência e pobreza", Benjamin aduz a constatação de uma crise não apenas individual da experiência, mas também de toda a humanidade. A transição dramática de uma sociedade pré-capitalística baseada na produção artesanal para um "monstruoso desenvolvimento da técnica" (BENJAMIN, p. 115, 1994) legou a perda da transmissibilidade da experiência e o empobrecimento do narrar. A sociedade industrial, ao mesmo tempo que mudava as bases da organização produtiva, mudava as bases da produção narrativa. No centro disso tudo, tal como os combatentes da primeira grande guerra, o frágil corpo humano e o silenciamento.

Sugere Gagnebin (1994), ao prefaciar o primeiro volume das obras escolhidas de Walter Benjamin (1994), que três são as constatações a que o filósofo chegou sobre o declínio da experiência na era do capital: 
a) a perda da experiência transmitida pelo relato como elemento comum ao narrador e ao ouvinte;

b) a extinção paulatina das organizações do trabalho pré-capitalistas, em especial o artesanato;

c) o afastamento da experiência da função prática da narrativa tradicional.

Uma comunidade fundada em experiências compartilhadas, transmitidas de geração em geração, baseada em uma dimensão prática do trabalho e refletida em uma cumplicidade entre o narrador e o ouvinte cede lugar ao mundo do aceleramento da produtividade, da perda do sentido do trabalho e, sobretudo, da defasagem da experiência entre uma geração e outra.

Visto por Benjamin (1994) como resultado do depauperamento da experiência no mundo industrial, o declínio da arte de contar representa o fim de uma tradição baseada na memória comum e no encontro entre a mão e a palavra. O gesto criador e cheio de sentido do artesão, que domina sua técnica e investe de significado todo o processo de transmutação da matéria pelo trabalho, é substituído pelo ritmo incessante das primeiras máquinas, da perda do tempo da criação e do som das bombas. Se o hiato que separava as gerações guardava a experiência dos anciãos como um saber prático e relevante para a continuidade da comunidade, o estrondo da Primeira Guerra Mundial representou o ápice do emudecimento da experiência e o fim de uma era.

Atualmente, como lembra Agamben,

[...] sabemos que, para a destruição da experiência, uma catástrofe não é de modo algum necessária, e que a pacífica existência cotidiana em uma grande cidade é, para esse fim, perfeitamente suficiente. Pois o dia-a-dia do homem contemporâneo não contém quase nada do que seja ainda traduzível em experiência: não a leitura do jornal, tão rica em notícias do que lhe diz respeito a uma distância insuperável; não os minutos que passa, preso ao volante, em um engarrafamento; não a viagem às regiões ínferas nos vagões de metrô nem a manifestação que de repente bloqueia a rua; não a névoa de lacrimogêneos que dissipa lenta entre os edifícios do centro e nem mesmo os súbitos estampidos de pistola detonados não se sabe de onde; não a fila diante dos guichês de uma repartição ou a visita ao país de Cocanha do supermercado nem os eternos momentos de muda promiscuidade com desconhecidos no elevador ou no ônibus. $\mathrm{O}$ homem moderno volta para casa à noitinha extenuado por uma mixórdia de eventos - divertidos ou maçantes, banais ou insólitos, agradáveis ou atrozes -, entretanto nenhum deles se tornou experiência (2005, p. 21-22).

Esta incapacidade de tradução da experiência que não depende de nenhum acontecimento extraordinário, mas que se aloca no próprio cotidiano como forma de emudecimento, é, para Agamben (2005), o traço marcante da nossa época. O homem contemporâneo vive sob a constante ameaça da subsunção da experiência no dia a dia. Filho do trabalho ubíquo da sociedade pós-industrial, o homem 
contemporâneo vive o declínio da experiência imerso em uma subsunção real e permanente da vida. Com o tempo todo mobilizado para a produção e o consumo, a subjetividade contemporânea não necessita mais de uma guerra de proporções planetárias para efetivar sua distância da experiência. O inexperienciável pós-moderno está entranhado na carne dos dias. O frágil corpo humano do século XXI está entrincheirado no acúmulo de dívidas, no sequestro constante da atenção, na obsessão por segurança, na ausência de alternativas políticas (NEGRI; HARDT, 2014), na velocidade vertiginosa da jet society (VIRILLIO, 1999, p. 192).

Reverberando Benjamin e Agamben, Jorge Larrosa (2004) distingue quatro inibidores da experiência na atualidade. Em primeiro lugar, Larrosa define o sujeito moderno como alguém ultra-informado, sedento de informação e, ao mesmo tempo, afogado em uma quantidade abissal de informação. Suspeita que a profusão incessante de informação que caracteriza o mundo atual seja uma estratégia de inibição de toda e qualquer forma de experiência. Destaca a necessidade de separar a experiência da informação. A quantidade absurda de informação que nos chega a todo o momento faz com que nada nos aconteça, "[...] uma sociedade constituída sob o signo da informação é uma sociedade em que a experiência é impossível" (LARROSA, 2004, p. 55).

"Em segundo lugar, a experiência é cada vez mais rara por excesso de opinião" (LARROSA, 2004, p. 155). O sujeito moderno não é só alguém obcecado por se atualizar das últimas notícias, possuir todos os dados, citar todas as fontes e referências, é também alguém que precisa ter uma opinião própria. Informar-se e emitir sua opinião. Vivemos na era do império da doxa. Não basta obter informação sobre tudo, mas, além disso, possuir opinião supostamente pessoal, supostamente crítica sobre tudo. A díade informação-opinião parece ter invadido até mesmo nossas ideias de aprendizagem. Boa parte das metodologias de aprendizagem coetâneas constrói circuitos que referendam esse dispositivo.

"Em terceiro lugar, a experiência é cada vez mais rara por falta de tempo" (LARROSA, 2004, p. 157). O sujeito moderno vive sob o paradoxo da aceleração do que permanece sempre o mesmo. A estratégia se aloja na captura do tempo, de todo o seu tempo. A mobilização infinita cria um aprisionamento da subjetividade, uma padronização acelerada de modos de ver, pensar, falar. Pacotes de linguagem, pacotes de possibilidades existenciais, pacotes de afetividade. Vendem-se ideais de felicidade da mesma forma que se vende um pacote turístico. Achatado pela falta de escolha, desrealiza-se na temporalização do trabalho ubícuo da sociedade pós-fordista. $\mathrm{O}$ sujeito moderno vive o tempo como um acúmulo de tarefas, uma agenda existencial que nunca para de crescer. 
Estamos exaustos e correndo. Exaustos e correndo. Exaustos e correndo. E a má notícia é que continuaremos exaustos e correndo, porque exaustos-e-correndo virou a condição humana dessa época. E já percebemos que essa condição humana um corpo humano não aguenta. $\mathrm{O}$ corpo então virou um atrapalho, um apêndice incômodo, um não-dá-conta que adoece, fica ansioso, deprime, entra em pânico. E assim dopamos esse corpo falho que se contorce ao ser submetido a uma velocidade não humana. Viramos exaustos-e-correndo-e-dopados. Porque só dopados para continuar exaustos-e-correndo. Pelo menos até conseguirmos nos livrar desse corpo que se tornou uma barreira. O problema é que o corpo não é um outro, o corpo é o que chamamos de eu. O corpo não é limite, mas a própria condição. O corpo é (BRUM, 2016, não paginado).

"Em quarto lugar, a experiência é cada vez mais rara por excesso de trabalho" (LARROSA, 2004, p. 158). Além de ser um sujeito que é bem informado e que opina, que hipotecou cada fagulha do seu tempo correndo incansavelmente de um lado para o outro, o sujeito moderno é um sujeito que trabalha. $\mathrm{O}$ paradigma do homem contemporâneo é a sua capacidade de produção. No entanto, não significa que essa capacidade de produção e os anos dedicados ao trabalho se revertam em experiência. Segundo Richard Sennet (1999), com todo o seu tempo comprometido em honrar suas dívidas, pouco resta para uma vida autoral e o controle de sua própria vida. Suas escolhas de trabalho e formas de existência vão se achatando, constituindo uma série de restrições e de perda de horizontes coletivos. Um dos efeitos perniciosos do endividamento é a personificação de problemas estruturais e sistêmicos da sociedade capitalista. O indivíduo cada vez mais assume sozinho a responsabilidade por suas dificuldades financeiras e psicológicas, destituindo-se de qualquer projeto coletivo de mudança social e de construção da experiência.

Diante desses quatro elementos, Larrosa (2004) propôe a necessidade de um gesto de interrupção, tal como os estudantes de Córdoba em 1918. Para que algo nos passe, para que algo nos aconteça, para que possamos fazer algo que constitua em experiência, é preciso de um gesto de insubordinação. Nos ecos de Córdoba, a universidade é intimada a repensar-se não somente enquanto instituição organizadora de um conhecimento, mas, sobretudo, como um modo de conhecer que posicione o sujeito da experiência no contexto da aprendizagem. Este sujeito, de acordo com Larrosa (2004), não é o da opinião, do trabalho, da informação, do julgamento. Trata-se do sujeito que é tocado pelo mundo de tal forma que, na relação com este mundo, se faz, se constitui. É como um espaço em que tem lugar o acontecimento. Um sujeito que, estando aberto aos acontecimentos, se expõe e, ao fazer isso, se põe no mundo.

No corrimão da denúncia do fim da experiência e, com ele, do aniquilamento do sujeito, o epistemólogo suíço Jean Piaget (2008) anuncia a necessidade da experiência como exercício vital, inerente aos percursos de aprendizagem. Confinado aos estágios do desenvolvimento da inteligência, o pensamento piageteano 
empobrece e pouco terá a contribuir com a formação do sujeito. Menos ainda, a interpretação da epistemologia genética, sua obra-prima, como um regulamento de testagens e ordenador das etapas escolares, estacionada na educação básica, terá seu potencial vivificado. Por isso é preciso, também, convidar Piaget a entrar na universidade.

\section{Piaget vai à universidade: a aprendizagem como experiência}

No debate acerca da universidade e de suas formas de ensinar, é preciso pautar a aprendizagem. Porque as grandes questões reivindicadas pelos estudantes de 1918 - que, de alguma forma, seguem presentes na atualidade - dizem respeito a este tema. Para tratar da aprendizagem, convidaremos para a conversa o maior epistemólogo de todos os tempos, o suíço Jean William Fritz Piaget (1896-1980). Quando limitada à educação infantil e anos iniciais, a teoria de Piaget é subutilizada. Restringe-se deveras, se não for compreendida como subsídio do desenvolvimento cognitivo para toda a vida. É preciso, portanto, chamar Piaget para entrar na universidade, lugar da aprendizagem do sujeito adultescente.

Aprender é condição do humano e, de certa forma, seus destino e sentido. Também restringe-se a contribuição de Piaget, se o foco de seus estudos concentrar-se nas etapas do desenvolvimento. Ele foi mais longe. Em sua epistemologia genética, sujeito e mundo interagem de tal forma que, no processo permanente de acomodação, se cria uma relação de familiaridade propiciadora do conhecimento ao longo de toda a vida.

Partindo do argumento empirista, Piaget (2008) reconhece o lugar indispensável da experiência para a aprendizagem. Como crítica ao empirismo, o autor constata com base em suas pesquisas que a experiência como uma pressão inequívoca do meio sobre o sujeito não é suficiente para o desenvolvimento da inteligência. É a atuação, em reciprocidade, do sujeito sobre a experiência que propicia a aprendizagem. Para ele, a experiência passa a constituir um dado da aprendizagem na medida em que compõe uma série histórica na qual encontra lugar onde se significar. Afirma que "A importância do meio só é sensível, com efeito, num desenvolvimento histórico, quando as experiências adicionadas opõem as séries individuais umas às outras o suficiente para permitir que se determine o papel dos fatores externos" (PIAGET, 2008, p. 338). Aquilo que o meio oferece ao sujeito adquire o caráter de experiência, quando produz um estranhamento e constitui-se como problema, como questão a ser investigada. Será a inteligência, enquanto acúmulo de experiências anteriores, e seu efeito intelectivo que potencializam nova organização da experiência presente, a significação dela, seus efeitos e desdobramentos. Decorre daí 
a relevância do contato interativo e recíproco entre sujeito e meio nas distintas etapas do percurso acadêmico, nunca substituível pelo discurso conteudista ou pela simples produção de opinião, como já nos alertou Larrosa (2004).

De modo geral, a presença do pensamento de Piaget na educação brasileira ficou bastante restrita às práticas construtivistas, priorizando a educação infantil e os primeiros anos do ensino fundamental. Entretanto, a proposta da epistemologia genética é mais abrangente, perpassando toda a vida do sujeito. Além disso, os estudos sobre o pensamento de Piaget, por um lado, focalizam, em geral, os estágios do desenvolvimento como um processo etapista no qual o estágio anterior é refutado pelo seguinte. As pesquisas de Piaget (2008), por outro, apresentam os estágios não como superativos, mas acumulativos. A relação entre as características da aprendizagem, em cada estágio, e a idade correspondente refere-se a fase da vida em que tais características se desenvolvem e não pretende limitar a ocorrência das características, mas sua predominância enquanto desenvolvimento. Se, por um lado, as fases se desenvolvem, segundo o autor, até por volta dos 15 anos de idade; por outro, a repetição dos esquemas cognitivos construídos nos quatro movimentos - sensório-motor, pré-operatório, operatório concreto e operatório formal - ocorre por toda a vida do sujeito.

Com base nos argumentos apresentados, pode-se afirmar que as múltiplas formas de organização da educação formal, nas distintas fases da escolarização, que desconsideram o papel da experiência no processo de aprendizagem, limitam a ação cognoscente do sujeito da aprendizagem, quando não a tornam inoperante. A compreensão da teoria de Piaget restrita aos estágios do desenvolvimento enquanto etapas tendem a organizar o ensino com restrições à experiência, na medida em que os anos escolares avançam. No entanto, a proposta de Piaget vai em sentido oposto, ao afirmar que: "em resumo, em todos os níveis, a experiência é necessária ao desenvolvimento da inteligência" (2008, p. 339). Ele entende, também, que a força da experiência como fonte de aprendizagem não diminui na medida em que se estrutura o pensamento de forma mais lógica. Segundo ele:

Poder-se-ia esperar, então, que o papel da experiência diminuísse em proveito de estruturações a priori. Mas tal não sucede. Em primeiro lugar, como os esquemas são sempre resumos de experiência, as suas assimilações recíprocas ou suas combinações, por muito refinadas que sejam, nunca exprimem mais do que uma realidade experimental, passada ou futura [...]. O papel da experiência, longe de diminuir da terceira para a quarta fase, só faz, portanto, aumentar de importância. Durante a quinta fase, a utilização da experiência ainda mais se amplia, pois esse período é caracterizado pela "reação circular terciária" ou "experiência para ver" e a coordenação dos esquemas prolonga-se, doravante, em "descobertas de novos meios por experimentação ativa" (PIAGET, 2008, p. 338-339). 
Considerando uma compreensão etapista acerca do pensamento de Piaget, a organização do ensino e as dinâmicas curriculares fundamentam seus planejamentos na passagem do concreto (como experiência) para o formal (pensamento lógico-intelectivo), como se o sujeito dispensasse a experiência por ter desenvolvido o pensamento operatório-formal. Tal compreensão é equivocada e não encontra fundamento nas pesquisas do epistemólogo suíço. Ao contrário, segundo Piaget (2008), a experiência, enquanto uma contribuição do meio para a ação cognitiva do sujeito, se apresenta cada vez com mais exigência, na medida em que a inteligência se complexifica por seu próprio desenvolvimento. E, cada vez mais necessária será a atuação do sujeito sobre a própria experiência. Segundo o autor, o desenvolvimento cognitivo "não acentua o papel isolado da experiência, mas destaca a atividade do sujeito que torna possível essa experiência" (PIAGET, 2008, p. 337).

Com mais clareza e ênfase, ainda, ele destaca: "Por outras palavras, o contato com as coisas é menos direto no começo do que no fim da evolução prevista" (PIAGET, 2008, p. 341). Longe de dispensar a experiência, portanto, o sujeito que já desenvolveu o pensamento lógico-operativo necessita da relação com o meio, tanto para testar suas hipóteses, já mais elaboradas, como para, pelo processo interativo, transformar a realidade. É essa a condição indispensável para o reconhecimento do sujeito enquanto tal.

Ao acolhermos os argumentos de Benjamin (1994) e de seus comentaristas, bem como os de Piaget (2008), torna-se necessário repensar a pedagogia universitária no sentido de propiciar a experiência, colocando-a no centro do processo de ensino e aprendizagem. Para tanto, a indissociabilidade constitui-se chave de compreensão metodológica e caminho para a mobilização orgânica e estruturada das metodologias que se pretendam inovadoras na educação superior. A extensão, se compreendida a partir do enfoque da aprendizagem, pode formular-se como o núcleo desencadeador de uma nova pedagogia universitária. Como abertura e contato com a realidade, a extensão é recurso experiencial da aprendizagem, quando integrada ao currículo, numa lógica da indissociabilidade. A partir dessa compreensão, também é possível repensar a proposta de formação docente para a educação superior. A compreensão do processo de aprendizagem fornece subsídios para os professores reconstruírem suas formas de ensinagem, porque, conforme Nogueira, retomando Freire:

Aprender, do ponto de vista histórico, precedeu o ensinar. Foi aprendendo que se aprendeu a ensinar. E não o contrário. A prática fundante do ensino é o aprendizado, tendo reconhecido que aprenderam, o homem e a mulher descobriram que, embutida no aprendizado, vinha a capacidade de ensinar, um problemão surgiu quando se burocratizou a relação educador-educando. Neste caso, preocupou-se com sistematizar apenas o ensinável... (NOGUEIRA, 2004, p. 48). 
Vale ressaltar que o pensamento de Freire não está longe do de Piaget, e o pensamento de Piaget não está longe do de Benjamin. Em muitos aspectos, a compreensão da aprendizagem proposta por Freire ancora-se na epistemologia genética e na valorização do saber feito de experiência. Compreender como as pessoas aprendem é condição basilar para saber como se pode ensinar. No ambiente universitário, naturaliza-se o ensino instrucionista, conteudista e abstrato. A grande questão inerente ao Manifesto de Córdoba e à provocação embutida no princípio da indissociabilidade consiste em repensar o posicionamento do sujeito aprendente, conforme compreendido pela epistemologia genética, na pedagogia universitária. Vejamos como a extensão universitária pode ajudar em tal reposicionamento.

\section{A potência pedagógica da ação extensionista}

Por constituir-se como presença contextualizada, a extensão possibilita a experiência mobilizadora da aprendizagem de tal forma partícipe e constituidora da subjetividade que decorre dela - aprendizagem - a transformação do meio (mundo). Para Piaget, "Toda e qualquer outra forma de registro da experiência, além da associação sob as suas diferentes formas [...], supõe, com efeito, uma atividade intelectual que participa na construção da realidade exterior percebida pelo sujeito" (2008, p. 340).

Existe uma linha de costura que interliga as reivindicações dos estudantes de Córdoba, a denúncia do fim da experiência, as preocupações da epistemologia genética e os desafios atuais da universidade. O manifesto de 18 problematizava radicalmente um modo de ensinar, uma postura pedagógica dos professores que impossibilitava a presença ativa do sujeito cognoscente, construtor e transformador do mundo.

Com forte influência do racionalismo, o ensino universitário, como tradicionalmente vem sendo organizado, é insuficiente à dinâmica cognoscente do sujeito aprendente. A extensão, por sua natureza dialógica com a comunidade e as problemáticas dela decorrentes, configura-se como locus privilegiado no exercício da experiência proposta por Piaget (2008). Os extensionistas, conforme postula Freire (1983), tocados pelos contextos em que a vida flui sem os artifícios de um método pré-estabelecido, permitem a pergunta constituidora do problema e mobilizadora da curiosidade que, no exercício dialógico, possibilita a aprendizagem que transforma o real.

A pedagogia universitária que pretenda a autonomia do sujeito, o exercício do conhecimento transformador e a consequente formação cidadã será aquela pautada pela metodologia que tenha como ponto de partida a realidade e suas proble- 
máticas. É nesse sentido que a concepção de pedagogia alarga seus horizontes, saindo das reduzidas definições metodológicas, e alcança o estatuto de uma ciência da educação capaz de inserir-se nas distintas dinâmicas culturais que ensejam $o$ exercício fecundo da aprendizagem. É a potência pedagógica que habita a pergunta, nascida da relação entre sujeito e meio, que mobiliza a inteligência, sustentada pela curiosidade, impregnada de conhecimentos anteriores, construídos em outras experiências, a construir novo conhecimento. Freire, recuperado por Nogueira, é contundente, quando afirma:

Nós nos humanizamos a partir de desenvolver/aprimorar a curiosidade. Em seguida, nós nos humanizamos quando, com curiosidade, inventamos o saber. Terceiro, nos demos [sic] conta de que, mesmo sendo uma invenção ciente dos/nos humanos, [...] a curiosidade é algo inerente à vida; portanto, ela é mais ampla do que o projeto humano, ela é vital (NOGUEIRA, 2004, p. 71).

A curiosidade, motor operacional da aprendizagem, é acionada a partir do contato com certo objeto, problematizador de um campo de compreensão já estabelecido. Tal fenômeno foi designado por Piaget (2008) como desequilibração. A curiosidade pode ser ingênua ou epistemológica (FREIRE, 2007). Ingênua, quando seu despertar tem um fim utilitarista; epistemológica, quando a pergunta mobilizadora situa-se no campo do sentido, da existência. Ambas não são antagônicas. Trata-se de um trajeto que vai de uma a outra e, se bem conduzido, possibilita complementariedades entre elas. Reside aí, nesta condução, o trabalho pedagógico, foco da atividade do educador. É neste campo, também, que se localiza a experiência enquanto uma vivência produtora da aprendizagem, tanto por seu caráter constituidor da subjetividade como por sua repercussão no mundo.

Na dinâmica curricular tradicional, pautada pela predominância do ensino como instrução e da pesquisa e da extensão como atividades isoladas, adicionais e desintegradas de tal dinâmica, o sujeito cognoscente não se reconhece em sua total potencialidade aprendente e transformadora. Muitas vezes, as manifestações de desinteresse por parte de estudantes e as práticas repetitivas e desestimulantes por parte dos professores vinculam-se ao modo de organizar o ensino com a predominância da fragmentação e do distanciamento da realidade, desintegrando, também, o sujeito aprendente. É neste interlúdio, entre a abertura desequilibradora e a receptividade assimiladora, que a experiência se faz indispensável para que, por meio da aprendizagem constituinte, o sujeito se exponha como presença histórica. 


\section{Palavras finais}

Ao celebrarmos o centenário do Manifesto de Córdoba, constata-se a impossibilidade de pensar-se a extensão universitária fora do tronco neural da educação que é a aprendizagem. E não se pode tratar da aprendizagem fora da experiência. Nesta discussão, vimos, por um lado, a abstenção do exercício da experiência, produzida pelo motor industrial que movimenta a máquina capitalista do último século; por outro, a negação da experiência como fonte da aprendizagem no universo organizacional do ensino.

Nas reflexões de Benjamin (1994) e Piaget (2008), constatamos a suspeita na ineficácia empirista enquanto imposição do meio sobre o sujeito; observamos também a questão da autoria da experiência pela atuação do sujeito tanto como narrador quanto como significador daquilo que é experienciado. A universidade, em seu irrefutável papel de formadora da cultura, tem, na extensão, a possibilidade de ressignificar sua função de produtora do conhecimento. Tanto para o filósofo como para o epistemólogo, a experiência é meio e, no percurso construtor da cultura, precisa desaparecer enquanto tal, para, por um lado, dar lugar à narração significada e, por outro, potencializar a inteligência que se torna cada vez mais complexificada quanto mais produtiva for a experiência.

Benjamin (1994) questionou-se acerca do valor do patrimônio cultural, se esse não for vinculado à experiência. Pelo mesmo fio condutor da indagação, prorrompe a pesquisa de Piaget (2008), que não encontra relação entre sujeito e meio sem a participação ativa do primeiro como significador e produtor do segundo. A potência pedagógica da extensão como elemento curricular, portanto, encontra-se no fato de constituir-se como experiência no sentido tanto de expor o sujeito cultural como de subsidiar a aprendizagem do sujeito cognoscente.

Os argumentos desenvolvidos neste estudo, as evidentes manifestações de necrosamento do modelo instrucionista da educação e os apelos legais para um novo momento da educação superior mobilizam os desejos, as energias institucionais e as políticas públicas para uma universidade que propicie a formação viva, dinâmica e significativa dos jovens do século XXI. Neste intento, certamente, após cem anos do Manifesto de Córdoba, com incontáveis e bem-sucedidas propostas de gestão da extensão universitária, cabe à educação superior reestruturar sua pedagogia, contando com o papel produtivo da humanidade presente na experiência. 


\section{Referências}

AGAMBEN, Giorgio. Infância e história. Belo Horizonte: Editora da UFMG, 2005.

BENJAMIN, Walter. Magia e técnica, arte e política. São Paulo: Brasiliense, 1994.

BRUM, Eliane. Exaustos-e-correndo-e-dopados. El País, 4 jul. 2016. On-line. Disponível em: <http://brasil.elpais.com/brasil/2016/07/04/politica/1467642464_246482.html>. Acesso em: 30 set. 2016.

FREIRE, Paulo. Extensão ou comunicação. 7. ed. Rio de Janeiro: Paz e Terra, 1983.

Pedagogia da Autonomia: Saberes Necessários a Prática Docente. 36. ed. Rio de Janeiro: Paz e Terra, 2007.

. Pedagogia da esperança: um reencontro com a Pedagogia do Oprimido. 15. ed. Rio de Janeiro: Paz e Terra, 2008.

GAGNEBIN, Jeanne Marie. Prefácio. Walter Benjamin ou a história aberta. In: BENJAMIN, Walter. Magia e técnica, arte e política. São Paulo: Brasiliense, 1994. p. 7-19.

LARROSA, Jorge. Linguagem e Educação Depois de Babel. Belo Horizonte: Ed. Autêntica, 2004.

MANIFESTO de Córdoba. 1918. Disponível em: <https://manifiestodecordoba1918.blogspot. com/2008/03/reforma-universitria-de-1918-da.html>. Acesso em: 23 jun. 2018.

NEGRI, Antonio; HARDT, Michael. Declaração: Isto Não é um Manifesto. São Paulo: Ed. Sesc/N-1, 2014.

NOGUEIRA, Adriano (Org.). Estendendo fronteiras: a extensão e a pesquisa na formação do educador. 2. ed. Taubaté: Cabral, 2004.

PIAGET, Jean. O Nascimento da Inteligência na Criança. 4. ed. Rio de Janeiro: LTC, 2008.

SENNET, Richard. A Corrosão do Caráter: conseqüências pessoais do trabalho no novo capitalismo. Rio de Janeiro: Record, 1999.

VIRILLIO, Paul. La inseguridad del territorio. Buenos Aires: La Marca, 1999. 